fective integration of the returning refugees; the relationships between refugee-specific development assistance and general development assistance, specifically, how to avoid developed states simply reallocating existing funds to refugee-generating states, effectively penalizing those governments which do not produce refugees; and a reasonably clear definition of those kinds of development assistance which should most logically be funded in order to achieve the baseline objective of assisting the reintegration of refugees.

In the balance of this edition of Refuge, we extract portions of the analysis offered by each of the Studies in Action, the key questions raised by those invited to discuss this research, and the conclusions arrived at both in the Workshops devoted to each of the five "building blocks" and in plenary session. The Studies in Action have been substantially abbreviated for this edition and therefore do not capture the full scope of the authors' work. Anyone interested in exploring the ideas more fully or in using these papers as reference materials should consult the originals. Full versions of the papers will be available in published form in mid-1996. The papers in their entirety offer a comprehensive exploration of the critical elements involved in reform and provoke meaningful debate about some of the fundamental concepts involved in protecting refugees. Anyone interested in reading the full versions is encouraged to consult the information at the end of this edition.

What is presented here is a work-inprogress. Some of the questions and concerns remain to be answered. The research is ongoing, and we welcome the participation of readers in our work. As we now move to the next phase of the project, we are seeking broad consultation. Please consider becoming involved. Again, details are provided at the end of this edition. We are extremely grateful to all those who have worked with us to-date, and look forward to benefitting from the advice of new participants in this Project.

James C. Hathaway Guest Editor

\title{
Some Thoughts on the Ethical Dimensions of the Project to Reformulate International Refugee Law
}

\author{
John Haley
}

The Reformulation Project was initiated from the conviction that the present system for the protection of refugees is seriously flawed. These flaws can affect those seeking protection. They can also affect those providing protection. All of these perceived flaws have a moral/ethical dimension.

Access to the system by those in need has always been a matter of moral concern. This concern has grown as various nation-states have placed more and more barriers to access, either unilaterally or conjointly with other states. This includes the need to cross an international border, into an- is morally and ethically wrong, especially when the results may well have life and death implications.

Still another example of a flaw in the present system is that countries of the North spend an enormous amount of money on their own particular determination processes. This provides protection to only a small minority of the world's refugee population. Over 80 percent of the world's refugees remain in theSouth. Their protection needs are primarily met by the UNHCR, operating on a budget which is one-quarter that spent on refugee determination in the North.

\section{Access to the system by those in need has always been a matter of moral concern. This concern has grown as various nation-states have placed more and more barriers to access, either unilaterally or conjointly with other states.}

other state, in order to be eligible for refugee status. Recently, states have made increasing use of deliberate strategies to interdict the flow of refugees, thus seriously inhibiting the ability of those in flight to seek protection from the international community.

A second flaw in the current system is that success rates of claimants are widely divergent. Those coming from similar situations should experience largely similar results. After all, the various countries which are parties to the Convention are using the same definition. But this is not the case. The definition is not applied in a uniform manner. The differences can be extreme. To subject refugee claimants to an uneven application of the definition

John Haley is a former member of the Immigration and Refugee Board, Ottawa, presently engaged in counselling and spiritual direction.
Several other limitations in the current system have an impact upon those seeking protection. There has been a growing recognition that the current definition fails to protect claimants who are genuinely fearful of serious harm, but who cannot establish that they are at differential risk because of their civil or political status-the core of the present definition. Regional agreements in Africa and the Americas have recognized this and extended protection on a broader basis. The conceptual narrowness of the definition needs to be addressed if protection is going to be effectively and equitably available to all those in need.

There is a conundrum in the present system. The claim for protection may be favourably determined on a group basis when it can be established that the claimant is a member of a group that is at risk. However, thereafter, that group-linkage is largely ignored. The 